\title{
On Line Instruction: An Opportunity To Re-Examine And Re-Invent Pedagogy
}

Irene Rosenthal, College of St. Rose, USA

\begin{abstract}
Author recounts ten discoveries she made about on-line instruction that were beyond her field of vision when she was still viewing it though the lens of traditional classroom instruction. The discoveries include what she learned by reviewing the research in effective course design and a discourse analysis she conducted of the number and types of ideas exchanged during two asynchronous discussions.
\end{abstract}

Keywords: on-line instruction, pedagogy, computer mediated communication, discourse analysis.

\section{INTRODUCTION}

$Q$ s a literacy educator, I rely on schema theory (Anderson, 1977) to understand the basic building blocks of learning. The simplest model of effective instruction, I tell my students, is to identify what a child already knows and then determine how to best connect what you are trying to teach to their already established understandings. This streamlines the process except when what you are trying to teach directly contradicts what children already know. Then it is important to understand that you will need to convince as well as to instruct.

Schema theory can be used to explain my own reluctance to explore on-line instruction and I am guessing the reluctance of many veteran college teachers who have not yet tried it. Before I taught my first hybrid, on-line graduate course, my opinion of on-line instruction was framed not by what it, in fact, is but by what it is not. My schema for the in-class experience I tried to provide for my graduate students where they could "live in the moment of discussion" and arrive at new levels of thinking would not be available to them on-line. My question in discussing on-line formats was always, "Where is the joy in this model?" I could not imagine what instruction could be like if it did not include the instructional elements that I knew worked for me. Through the years, I had developed a fairly standard approach to graduate instruction. The formula involves assigning the most worthwhile reading I could find on the topic to be discussed, providing a certain perspective on the topic in what I hoped were fairly thought provoking, interactive presentations, having students work in groups to apply the new learning and then engaging in a more critical discussion of the topic. Although small group discussion where students reported back discoveries to the whole class were an integral part of my classroom, my role in facilitating knowledge construction was central. I decided on discussion topics and I commented on whatever insights emerged from these discussions.

One of the reasons I agreed to teach a hybrid, on-line course last summer was specifically to either challenge or confirm my negative perceptions about on-line instruction. In order to continue to be an outspoken critic whenever administrators encouraged developing on-line courses for what I assumed were pecuniary considerations, I needed to understand on-line instruction from the inside out. The course, an elective in a Literacy masters' level program, was designed to introduce students to the range of materials available to teach K-6 language arts and to show them how to establish criteria in selecting and using such materials. The course was designed to fit into a three week summer immersion framework. We met three times on campus and students were assigned to participate in nine on line discussion sessions to process the assigned daily "readings." The class consisted of 20 graduate students in education.

I am pleased to report that my experience in teaching this course confirmed my original perception; it was nothing like the instructional model I had been practicing for many years. What I could not predict based on my old schema was that effective on-line instruction is something brand new. In doing the research to prepare for the 
course, I began to realize that if I had tried to replicate the in-class formula, the course would have probably been as dismal as I feared it would be. The opportunity to review pedagogical issues that I had taken for granted through the years was the first of many unexpected benefits I encountered through this venture. In order to orchestrate a successful learning experience for my students on-line, I needed to re-think what my role as the teacher in such a course would be, what kinds of interactions with information would sustain students at their keyboards and how they could share these interactions in discussion that would stretch their level of thinking, largely without a lot of direction from me.

I have become a proponent of on-line instruction and I would like to share ten discoveries I have made about it that were beyond my field of vision when I viewed it though my in-class lens. The first four points reflect discoveries I made by reviewing the research before I taught the course and were reflected in the course design. The last six points reflect discoveries I made by assessing the course both during and after its implementation.

1) One of my first discoveries in setting up the course was that I needed to be much more critical in the decisions I made in choosing the texts students would be examining. Since most of their class-time was to be spent interacting with these texts independently, I gave them access to a much wider range of materials in terms of both form and content. For example, instead of having them read a text book about best practices in using literature in the classroom, I had them watch videos of teachers (www.learning.org) actually using literature and had them critique these models. Our review of beginning reading programs involved comparing individual publishers' web-sites with http://ies.ed.gov/ncee/wwcl, a government clearinghouse that reviews the research on such programs. These on-line assignments did not serve as a pale imitation of what would have happened in class. They essentially changed the nature of the instruction making it more authentic and giving the students more opportunity for directly interacting with and evaluating the materials we were discussing.

2) I also realized that the discussion board and the blog entries now constituted "class time" so I spent much time researching how to best structure the requirements for both. It is in this area of computer mediated communication that the research is currently exploring the real potential of on-line instruction. In his research review, Luppicini (2007) concludes that there are partial advantages in CMC formats in terms of student writing, task focused discussion, collaborative decision making, group work and active involvement in knowledge construction during group interaction. Specifically, Chou \& Liu (2005) reported higher levels of learning in a web-based environment when compared with a traditional environment. Orr (1998) reported that $\mathrm{CMC}$ extended the depth and quality of discourse opening up new areas of discussion. Based on the research, students in my class were divided, somewhat randomly (Pimental, 1999) into four groups and these groups remained stable throughout the course (Bernard \& Lundgren Cayrol, 2001). After experimenting with synchronous postings, we decided to relax the time constraints and post asynchronously.

3) I re-examined the role I would play as the instructor. Although I still provided information and guided learning through several media-streamed lectures, my role was much less central to the daily transactions students made with the resources designed to establish their knowledge of course content. I found that much of my "instruction" occurred before the actual course began as I structured the learning experiences students would have. My role during discussions on discussion board took 'teacher as facilitator' to a whole new level for me. I rarely participated except to introduce the discussion topic and to synthesize what had transpired toward the end of every discussion. It should be understood that students were aware that I was "lurking" about the discussion board but I did not intrude on their collaborative efforts at meaning making as they worked their way through daily topics. What I did instead to support their discussions with additional information and clear up areas of confusion was to establish a separate forum, "Ask the Professor." They were asked them to check it regularly.

4) I carefully established accountability measures for every aspect of class participation. Palmer, Holt \& Bray (2008) ,Choi, et al., 2005, and Pimental, (1999) all suggest that specific guidelines be established to maintain a standard of academic rigor and student accountability in on-line discussion. Therefore, students in my course understood that they were required to contribute at least two substantive postings each evening and that these would be evaluated with a rubric in terms of their comprehensiveness, relevance, reflectiveness and effort to respond to other postings.

5) In reviewing the posts to the discussion board, I was soon impressed at how tenacious students seemed to 
be in their joint construction of meaning from the tasks I had assigned. I therefore engaged in an analysis of their discussion board posts using a coding system grounded in the data itself (Glaser \& Strauss, 1967) to determine emerging patterns of idea sharing a nd building. The fact that I was interested in idea construction rather than discourse patterns is based on Marshall's work, (1989) where discourse is categorized into discrete idea units and then classified according to the purpose they serve (direct, inform, question, respond to previous remarks). It is a form of open coding (Strauss \& Corbin, 1990) where descriptive notes are taken on the transcripts and categories are formulated that are then organized and reduced. My basic research questions were, "What are students attempting to accomplish in their discussion board posts?" and "Is there evidence of joint construction of new understandings through this discourse?"

Previous studies of discourse analysis of on-line discussion were helpful. Yeh (2010) identified thirteen behaviors, eight roles and four types of learning communities in asynchronous discussions among thirty-two preservice teachers. Liu, C.C. \& Tsai, C.C. (2008) categorized student contributions into nine possible types (issue, position, argument, group development, response, acceptance of response, objections to responses, conflict, support request. Ikpeze, C (2007) developed the following categories: elaborated responses, reflection, questions, propositions, argumentation and off task. Booth \& Hulten (2003) coded contributions as participatory, factual, reflective and learning. Perhaps most helpful was Gunawardena, Lowe and Anderson (1998) who analyzed the cognitive level of student discourse in an online discussion by using a format with the following categories: sharing and comparing of information, discovery and exploration, negotiation of meaning and co-construction of knowledge, testing and revision on ideas, and awareness of newly constructed knowledge.

I limited my analysis to two of the discussions by all four discussion groups. In the first discussion, students were comparing information on early reading programs using publishers' web sites and http://ies.ed.gov/ncee/wwc/. The second discussion required them to respond to models of instruction using literature in elementary classrooms by watching videos on www.learning.org

My coding system established six categories that could be used to describe students' posts in terms of what they were trying to accomplish. These simple categories were probably influenced by my many years as a reading specialist trying to decide just what K-12 students did in response to texts. The six categories found to be broad enough to describe all the posts were:

Inform: These were posts in which students responded to the assignment and basically reported back on information they had found.

Connect: Students made connections between what they discovered from the assignment and their own experience.

Question: Students expressed the need for more information on the topic.

Analyze: In these posts, students attempted to train a critical eye on the information presented by either comparing it to information from other sources to identify discrepancies or to interpret it in terms of factors not mentioned in what they had read. It was noted whether students provided evidence upon which they based their criticism.

Evaluate: Students expressed either positive or negative opinions of what they had read. It was noted whether they provided evidence for these opinions

New Ideas: Students' comments reflect that they have synthesized the information and have come to a conclusion or that their reflection has produced an original idea. It was obvious that these were the posts that took the discussion to a new level.

The following chart broadly describes the number and proportion of ideas that were exchanged by each category for both discussions.

\begin{tabular}{|l|l|l|l|l|l|c|}
\hline Ideas & Inform & Connect & Question & Analyze & Evaluate & New Ideas \\
\hline
\end{tabular}




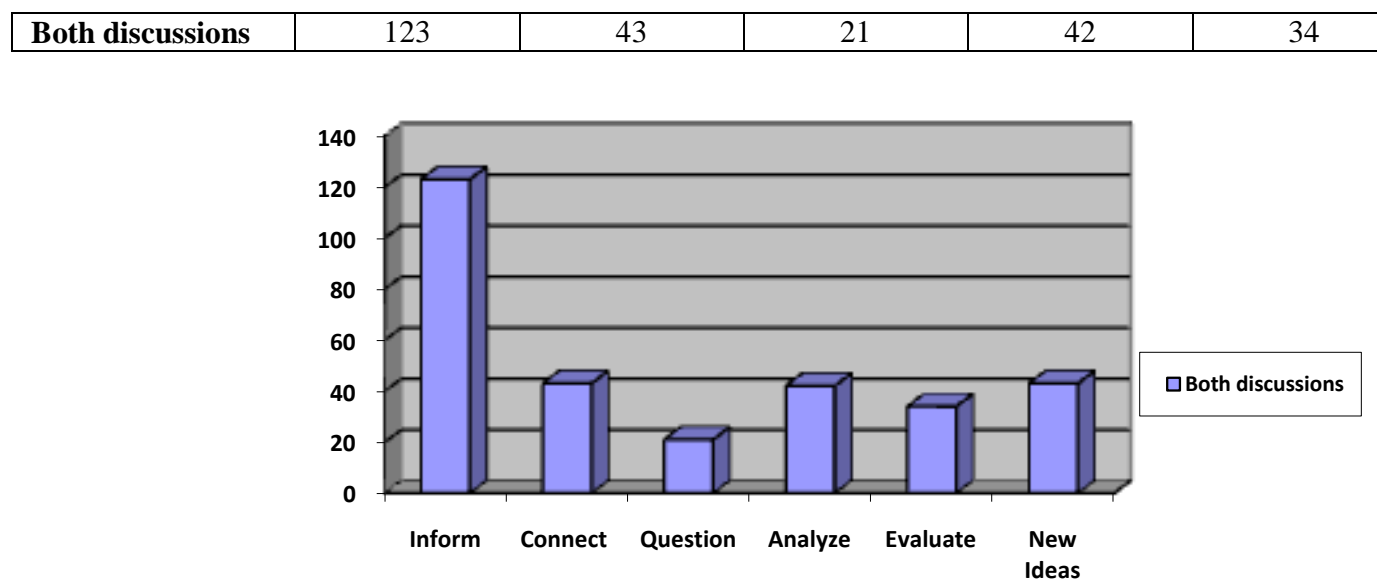

By aligning these idea units with Bloom's Revised Taxonomy (Anderson, et.al, 2001), an instructor can easily recognize that the units, 'inform,' 'connect,' and 'question' involve what are characterized as lower order cognitive skills. Students making these contributions were attempting to remember and comprehend the topic assigned. A total of 187 idea units in both discussions provided evidence of lower level cognitive skills. Units designated as 'analyze,' 'evaluate,' and 'new ideas' correlate with what Anderson, et.al categorize as higher level cognitive skills where students engage in more critical and creative responses to the topic. In both discussions 119 idea units represent evidence of higher order cognitive skills. Visually representing the ideas transacted in on-line discussion can serve as a valuable tool in both formative and summative assessments of the course's effectiveness. Frankly, I am quite satisfied with both the number of ideas generated per student in these discussions and the fact that $39 \%$ of the ideas exchanged involved students engaged in higher level thinking skills.

\begin{tabular}{|l|c|c|}
\hline Ideas & Lower Order & Higher Order \\
\hline Both discussions & 187 & 119 \\
\hline
\end{tabular}

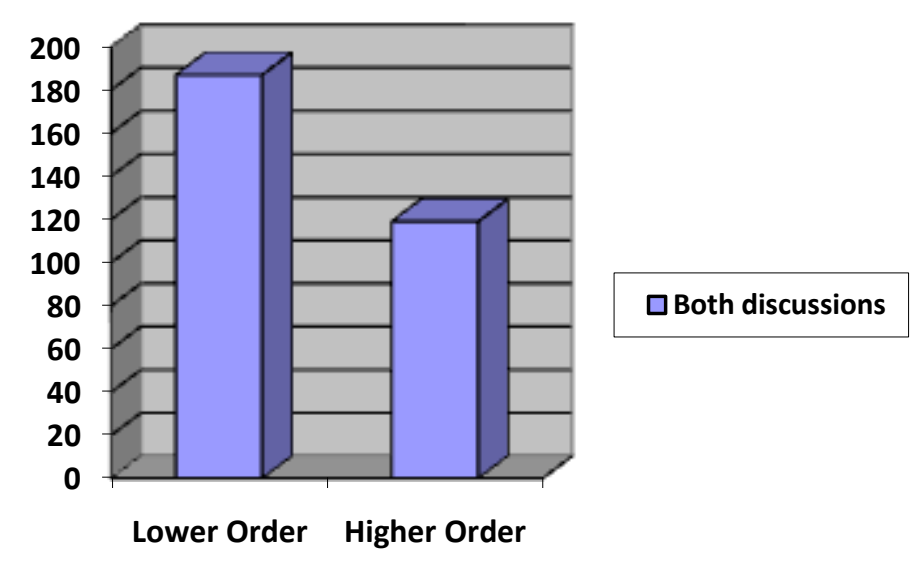

6) This exercise convinced me that the ability to review a written transcript of the ideas generated by each discussion topic within a course is itself an awesome pedagogical opportunity. Questions like, "What topics generated the most ideas? And "Which groups formulated the most new ideas?" have enormous potential to inform subsequent instructional decisions. If I were to teach this course again, I might reflect on the fact that Discussion A generated 30 contributions that were categorized as 'new ideas' whereas Discussion B produced only 13. I might rethink the fact that the group with only four participants (group 4) produced a total of 40 idea units as compared to the other groups of 5 members who produced 95 (group 1) and 67 
(group 2) ideas respectively. Group 3 which had 6 members produced 104 ideas.

\begin{tabular}{|l|c|c|c|c|}
\hline Group: & Group 1 & Group 2 & Group 3 & Group 4 \\
\hline Total Ideas: & 95 & 67 & 104 & 40 \\
\hline
\end{tabular}

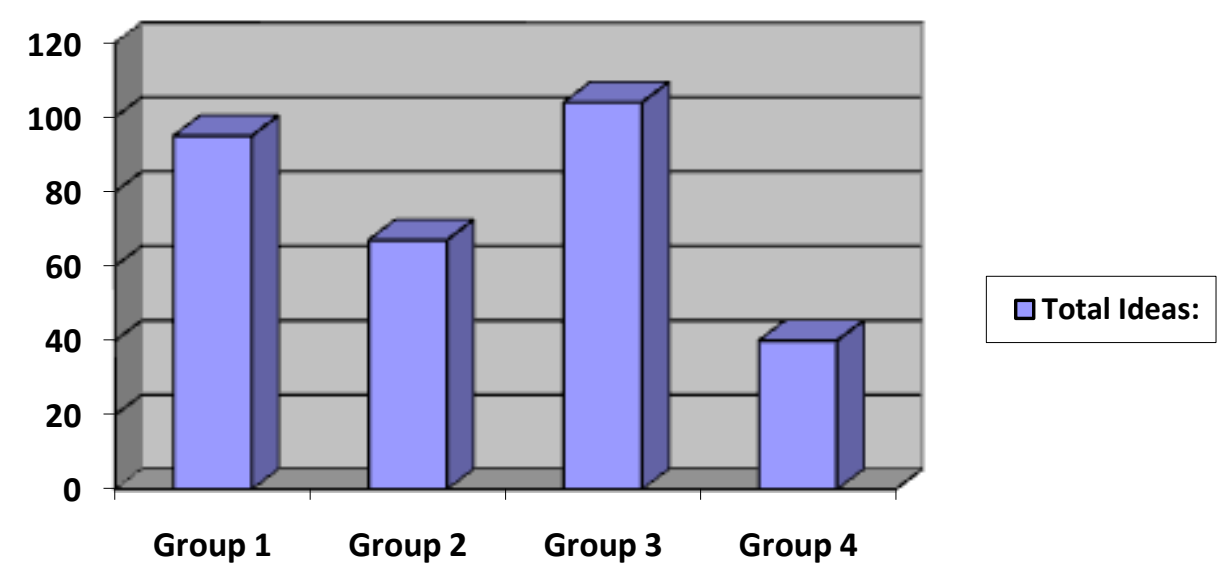

7) The analysis also underscored the fact that universal participation is a requirement for an on-line course. Although I understood, in theory, that students would be required to contribute two substantive posts per discussion, I was overwhelmed by the sheer number and length of the posts in terms of the ideas exchanged. The idea analysis revealed that 149 idea units were exchanged in Discussion A and 158 in Discussion B. This means that each student contributed a mean of 7.5 ideas in Discussion A and 8 ideas in Discussion B.

8) I have also become aware of the fact that having a written transcript of ideas can be used instructionally across sections and across semesters. I definitely intend to further study the 'new idea' category to try to identify when and how analysis spins itself into something new. What I will certainly do whenever I teach on-line again will be to integrate examples of "new ideas" from past courses into future discussions. As a matter of fact, students would be well served if they were presented with the opportunity to analyze a creative response from the past to the topic at hand and tried to understand what kind of thinking led to the response.

9) As a professor of writing, I could not help but notice that the writing students did in electronic forums (both posts and blogs), knowing that their classmates would read and respond, seemed to be clearer expressions of their thinking than more formal papers directed to me in other courses. There is a comfort level that students seem to experience in expressing themselves in an on-line environment. Their passion and sincerity came through loud and clear on many posts,

Overall, I feel as though we are all in agreement about how this information really is perturbing and difficult for us to stomach as future teachers. When commercialism and capitalism began to invade the education system on such a fundamental plane, I wonder who was there to try to stop the flashy lights of the 'quick fix' on literacy and reading issues.

10) What is perhaps most exciting is the opportunity this kind of reflection and analysis affords instructors to collaborate. Having the ability to document students in the process of forming their ideas will help us to discuss and compare our efforts in nurturing these ideas. In a word, these new technologies can help us get back to basics; to examine and articulate how ideas happen.

In conclusion, my experience in teaching in an on-line environment convinced me that my schema for 
college instruction was circumscribed by the four walls of my classroom. I now understand that there are exciting opportunities to facilitate student learning in environments beyond the here and now.

\section{AUTHOR INFORMATION}

Irene Rosenthal, Ph.D. is an Associate Professor of Literacy at the College of St. Rose in Albany, NY. She supervises classroom internships for graduate students in Literacy and is currently working on developing "writing boot camps" for middle school students. She can be reached at rosenthi@ strose.edu.

\section{REFERENCES}

1. Anderson, R. C. (1977). The notion of schemata and the educational enterprise in Anderson, R.C., Spiro, R.J., and Montague, W.E. (editors) (1984). Schooling and the acquisition of knowledge. Hillsdale, NJ: Lawrence Erlbaum.

2. Anderson, L. W., \& Krathwohl, D. R. (Eds.). 2001. A taxonomy for learning, teaching and assessing: A revision of Bloom's Taxonomy of educational objectives: Complete edition New York: Longman.

3. Bernard R. \& Lundgren-Cayrol, K.( 2001).Computer conferencing: An environment for collaborative project-based learning in distance education. Educational Research and Evaluation 7(2):241-261.

4. Booth, S \& Hulten. M. (2003).Opening dimensions of variation: An empirical study of learning in a webbased discussion. Instructional Science 31(1):65-86.

5. Brown, A. H. \& Green, T. (2009). Time students spend reading threaded discussions in online graduate courses requiring asynchronous participation. International Review of Research in Open and Distance Learning, v10 n6 Dec 2009.

6. Chou, S \& Liu, C. (2005). Learning effectiveness in a web-based virtual learning environment: A learner control perspective. Journal of Computer Assisted Learning 21(1): 65-76.

7. Glaser \& Strauss, (1967). The discovery of grounded theory. Chicago: Aldine Press

8. Gunawardena, C.N., Lowe, C.A. \& Anderson. (1998). Transcript analysis of computer-mediated conferences as a tool for testing constructivist and social-constructivist learning theories. Paper presented at Proceedings of the Annual Conference on Distance Teaching and Learning, August 5-7 in Madison, WI.

9. Ikpeze, C. (2007). Small group collaboration in peer-led electronic discourse: An analysis of group dynamics and interactions involving pre-service and in-service teachers. Journal of Technology and Teacher Education 15(3): 383-407.

10. Liu, C.C., \& Tsai, C.C. (2008). An analysis of peer interaction patterns as discoursed by on-line small group problem-solving activity. Computers \& Education, 50: 627-639.

11. Luppicini, Rocci. (2007). Review of computer mediated communication research for education. Instructional Science 35: 141-185

12. Marshall. J.D. (1989). Patterns of discourse in classroom discussions of literature (Report No. 2.9). Albany, NY: National Research Center on Literature Teaching and Learning.

13. Orr, P. (1998). HOWL: An on-line conference for an off-line poetry seminary. Computers and Composition 15(1):97-104.

14. Palmer, S, Holt, D., Bray, S. (2008). Does the discussion help? The impact of a formally assessed online discussion on final student results. British Journal of Educational Technology, v39 n5 p847-858.

15. Pimentel, J. (1999). Design of net-learning system based on experiential learning. Journal of Asynchronous Learning Networks 3(2) [On-line]. Available at: http://www.aln.org/alnweb/journal/Vol6 1 pimentel.htm.

16. Strauss, A., \& Corbin, J. (1990). Basics of qualitative analysis: Grounded theory procedures and techniques. Newbury Park, CA: Sage.

17. Yeh, Y.-C. (2010). Analyzing Online Behaviors, Roles, and Learning Communities via Online Discussions. Educational Technology \& Society, 13 (1), 140-151. 